\title{
The multimodal interactional work of having wonderful ideas
}

\author{
Benedikt W. Harrer ${ }^{1}$ \\ ${ }^{1}$ Department of Physics and Astronomy, San José State University, One Washington Square, San José, CA, 95192-0106
}

\begin{abstract}
Learning physics is socially organized through interactions with peers and more competent others. Instructors' and peers' assessment of and responsiveness to learners' ideas in the moment is critical for the collaborative construction of knowledge in physics. However, we still know little about how instructors and learners negotiate the value and productiveness of ideas. While to an outsider, some of the ideas physics learners discuss do not seem immediately valuable or productive for the problem being solved, Duckworth encourages us to pursue an "insider's view" on how learners experience their ideas. Building on this notion, I pursue an "insider's view" to better understand how peers and teachers experience each other's ideas. In particular, I examine the interactional methods and resources physics students use to express their ideas and to mark their own or others' ideas as wonderful or not-so-wonderful. I demonstrate how participants rely on a variety of multimodal communicational tools, including speech, words, gestures, and whiteboard inscriptions to negotiate wonderfulness, extending our current understanding of how peers and instructors are responsive to physics ideas in the moment.
\end{abstract}

\section{PROBLEMATIZING "WONDERFULNESS" "[W]onderful ideas ... need not necessarily look
wonderful to the outside world."}

-Eleanor Duckworth [1] (p. 14)

Imagine a smiling toddler in a high chair, spaghetti with tomato sauce spread out on the plastic surface in front of her, her hands drenched in sauce, sauce smeared across her face, and a spaghetti draped on her forehead. She is full of joy, having just discovered wonderful new facets of how nonsolid food behaves under certain experimental conditions. While her parents may not share her sense of wonder and wonderfulness for her newly-had ideas, research suggests that infants' messy, hands-on exploration of food plays a crucial role in their developing understanding of non-solid substances [2].

This scenario illustrates that the notion of wonderfulness deserves to be problematized. Who gets to decide that an idea is wonderful? The idea-haver themselves? A parent or teacher? A researcher? All of them? None of them? In my plenary talk, I proposed three possible ways of seeing wonderfulness: (1) learner-centered, (2) discipline-centered, and (3) interaction-centered wonderfulness. In this paper, I review these ways of seeing wonderfulness using an example of a pair of students in an algebra-based introductory physics course. I show that ideas are often had multimodally, and that establishing an idea as wonderful or not-so-wonderful is an interactional achievement.

\section{A. Learner-centered (or student's) wonderfulness}

According to Duckworth, a wonderful idea is had when somebody (a learner, a child, etc.) feels that something is "a significant thing to comment upon" [1] (p. 4). Students have to feel a genuine sense of ownership over an idea for it to truly be wonderful: "You don't have the idea unless you've created it" [3] (p.30). On the other hand, ownership of wonderful ideas to Duckworth does not mean "I know my ideas are right," but that the idea-haver is "willing to try out [their] ideas" [1] (p. 5). The various examples of wonderful ideas Duckworth observed led her to conclude that wonderful ideas are had in transitional moments, points in time when "a certain experience fit[s] into certain thoughts and [takes one] a step forward" [1] (p. 5).

Taken together, Duckworth's view on the wonderfulness of ideas is learner-centered. She seems to focus on a child's experience of an idea as wonderful. Whether a particular idea could be considered "correct" is not necessarily part of Duckworth's way of seeing wonderfulness.

\section{B. Discipline-centered (or teacher's) wonderfulness}

As teachers and researchers, we naturally gravitate toward an assessment and evaluation of learners' ideas based on their disciplinary value [4]. After all, we would like students to learn (and have) disciplinarily normative ideas about the physical world. Seeing wonderfulness based on whether an idea is (to some degree) aligned with disciplinarily sanctioned ways of seeing the world can stand in contrast to a learner-centered view of wonderfulness: Instead of seeing learners' ideas as wonderful in their own right, discipline-centered wonderfulness requires the use of external values and categories to evaluate an idea.

This is not meant to argue that discipline-centered wonderfulness is inferior to learner-centered wonderfulness. It is not enough to call a learner's idea wonderful just because it was shared, as was extensively discussed at the conference. On the other hand, only judging ideas based on whether they are aligned with or may - in the teacher's or researcher's eyes - lead to commonly accepted scientific understandings and ideas is problematic, as well. With a focus on only disciplinarily appropriate (or correct) ideas, the having of new and different ideas can be discouraged. As Duckworth points out: "The more we help children to have their wonderful ideas and to feel good about themselves for having them, the more likely it is that they will some day happen upon wonderful ideas that no one else has happened 
upon before" [1] (p. 14). This is especially desirable in science because scientific progress is made through innovative ideas that build on previous ideas.

\section{Interaction-centered (or co-constructed) wonderfulness}

To truly appreciate the wonderfulness of an idea, Duckworth argues that we have to pursue an insider's view on what the idea really means for the idea-haver. It sometimes is easy to dismiss a learner's idea as disciplinarily useless in the heat of instruction when, upon further inspection and in negotiation with the idea-haver, it might have been truly generative and desirable.

I take Duckworth's call for a pursuit of the insider's view further to examine how participants in regular classroom interaction may experience the wonderfulness of an idea. To do so, I use tools provided by Conversation Analysis [5].

Conversation Analysis (CA) assumes that all social interaction is orderly, and that this orderliness is ongoingly produced (co-constructed) by the participants in the interaction. Like many other sociological approaches, (e.g., ethnomethodology, interpretivist paradigms, social constructionism), CA sees people "as active participants in the construction of the social world" and is therefore set "in opposition to structural functionalist models of the social order" [6] (p. 167). CA aims to describe events from the participants' point of view and to uncover the intertwined construction of practices, actions, and activities to understand the organization of ordinary social activities. To pursue this research agenda, CA takes advantage of the myriad multimodal interactional resources [7] like talk, prosody, gestures, gaze, posture, etc. that participants publicly display during their conduct with each other.

For the purpose of investigating how participants negotiate and co-construct the wonderfulness of ideas, it is useful that in interaction, people tend to (simultaneously or subsequently) display analyses of each other's actions [8], often by displaying a stance [9] toward them by employing a multitude of multimodal interactional resources. These resources are available not only to the participants in the interaction to be responded to and acted upon, but also to the analyst. By paying attention to how these resources are used and attended to by the participants in the interaction, we can glean an insider's view on wonderfulness.

\section{STEVE AND SALLY'S WONDERFUL IDEAS ABOUT BALLS ON TRACKS}

In the following, I use the example of a student's ideas about balls on incline tracks to illustrate the three ways of seeing wonderfulness. I will show that the having of ideas can be (and often is) a multimodal achievement (i.e., ideas are often not or not only expressed in words), and that wonderfulness is an interactional accomplishment (i.e., establishing an idea as wonderful or not is done as coordinated activity of participants).
Sally and Steve (pseudonyms) were students in a firstsemester introductory, algebra-based physics class. This class uses a curriculum that is based on Collaborative Learning through Active Sense-Making in Physics (CLASP) [10] with a strong emphasis on conservation laws (energy conservation and momentum conservation). The course starts out with energy conservation in thermodynamics. After developing familiarity with energy models and representations (including the so-called EnergyInteraction Diagram [11]) in the thermodynamics part of the class, students then investigate energy conservation in the context of mechanical phenomena. The subsequent discussion of momentum conservation serves as a segue from energy to Newtonian mechanics. A Newtonian force model and elementary kinematics are introduced at the end of the semester.

Every semester, about 250 students take the course. These students are enrolled in a variety of majors, including life sciences, kinesiology, forensic science and justice studies, aviation, and engineering technology. The students meet once weekly for 80 minutes in a large, interactive lecture, but they spend the majority of their class time working in small groups during two weekly discussion lab meetings ( 2 hours 20 minutes each for a total of almost five hours per week). The discussion labs meet in sections of 20 25 students.

\section{A. Setting and context}

The episode I present here occurred during discussion lab meeting 11, about six weeks into the semester. The students had recently been introduced to mechanical phenomena involving energy transformations and transfers, and they had already practiced using the familiar-to-them energy representations to investigate and model simple mechanical scenarios. Here, they are asked to make sense of a new phenomenon: two billiard balls on incline tracks of different widths (see Fig. 1).

For this scenario, students are told to assume that the two balls are identical, that they undergo an identical change in height, and that any frictional effects are negligible for the modeling of energy dynamics. The students are supposed to answer the question, "Why does one ball go faster and get to the bottom before the other ball?" To get them started, the lab manual suggests that students model the energy dynamics of the scenario. In doing so, the students should find that there are indicators for three types of energy: (1) translational kinetic energy (the balls move down the track), (2) rotational
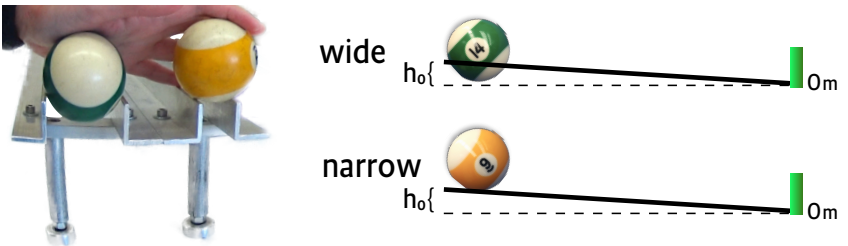

FIG 1. Two billiard balls on incline tracks of equal length but different widths. Both balls undergo the same height change. 
kinetic energy (the balls rotate as they roll down the track), and (3) gravitational potential energy (the balls undergo a height change from top to bottom of the track). Since frictional effects are to be neglected, the sum of the changes in all energy types is equal to zero (no energy is gained or lost by the system of ball and earth during the process):

$$
\Delta K E_{\text {translation }}+\Delta K E_{\text {rotation }}+\Delta P E_{\text {gravitational }}=0
$$

The energy conservation equation (1) is the same for both balls, so students have to recognize that the ball in the wide track rotates more than the ball in the narrow track. This is because the effective radius for rolling is smaller for the ball in the wide track. The ball has to rotate more to travel the same distance as the ball in the narrow track. With this observation, students can then conclude that more energy is necessary for the rotation of the ball in the wider track, which means that less energy is available for translation - the ball won't move down the track as fast as the ball in the narrow track, which will reach the bottom of the track first.

\section{B. Steve and Sally model balls on tracks}

Steve and Sally read the instructions in the lab manual. Sally quickly looks up, points to the ends of the tracks and says, "oh it's because it's different uh-", at which point Steve adds, "it's the widths. so, it's like- different on the surface area being put on it." He continues, "it rolls weirdly. it's likeit's a lot slower roll with this one [points to wide track]. and then this one [points to narrow track] is just a quick one."
While these observations are valid and in line with the expectations of the curriculum, the students have not yet modeled the energy dynamics of the balls. This may be why they do not interpret their observations further but instead repeat the experiment. After a brief silence, they turn around to the large whiteboard behind them and start to model the two balls using the Energy-Interaction Diagram.

Once they have derived the energy conservation equation (1), Steve and Sally notice that their energy model is the same for both balls. They turn to the tracks and conduct the experiment once more. Steve observes that the ball in the wider track "spins a lot more." He points to the model and equation on the board, elaborating, "rotation and translation will be different for one ball than [for] the other."

\section{Steve's physical intuitions about rolling}

After a little while, Sally points out that "OK, we have to answer why does one ball go faster than the other." Steve, who had been working on the white board, gets up, turns around, and responds with "it's because of the friction." Sally replies, "don't they have the same friction?" Steve picks up one of the balls, holds it between his two hands, carefully places his two middle fingers on two points at the bottom of the ball, while saying "no. because the point where the- the- it lies" (Fig. 2a). He then slides his index and middle fingers upwards on each side until they reach opposite points on the sides of the ball (Fig. 2b), explaining "so the wider I go the more s- the more spin- the more spin it gets" (Fig. 2c).

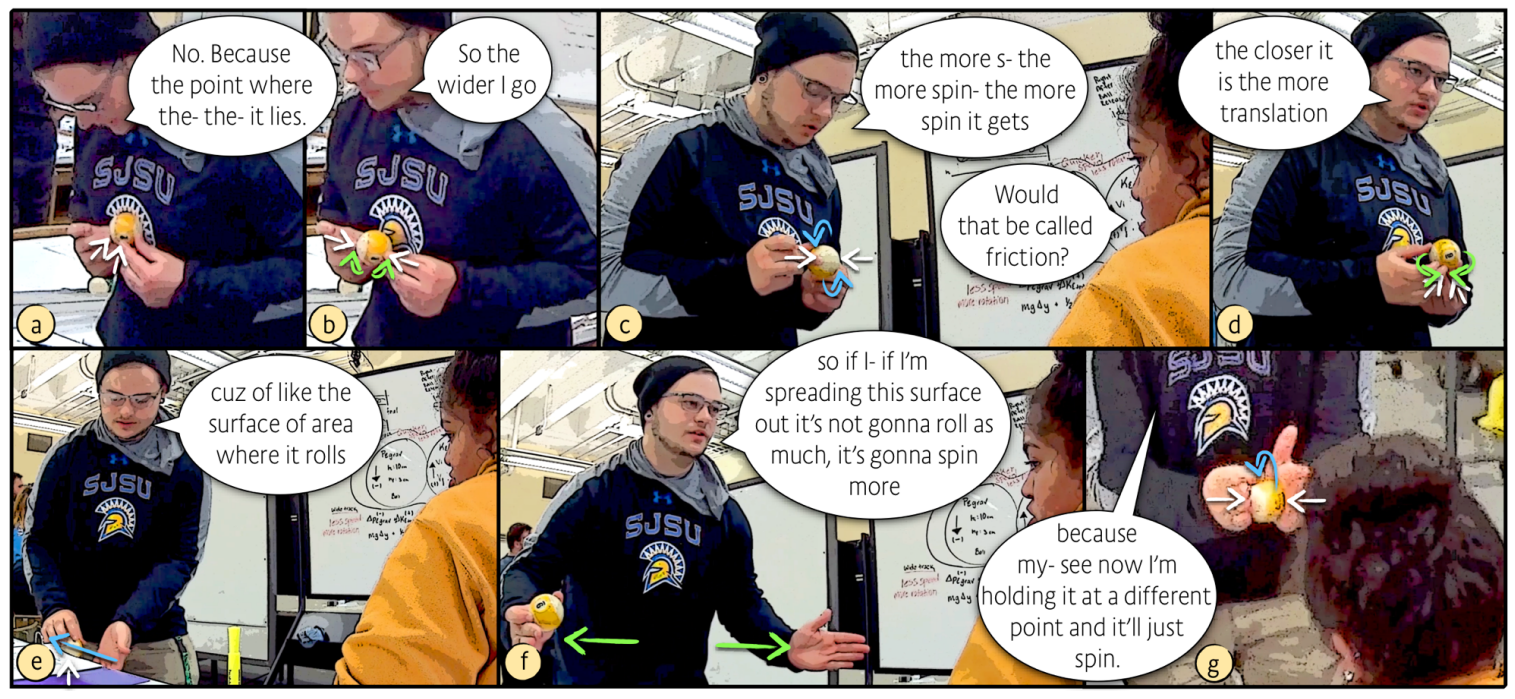

FIG 2. Steve's multimodally-had idea about rolling balls. White arrows represent indicated points of contact with a "surface," green arrows represent finger/hand movements, blue arrows represent movement of the ball.

While Steve is speaking and spinning the ball, suspended between his middle fingers, Sally asks, "would that be called friction?" (Fig. 2c). Focused on his explanation but reestablishing eye-contact with Sally (see restart in "the more spin- the more spin," Fig. 2c), Steve continues, "the closer it is the more translation" (Fig. 2d), while sliding his middle and index fingers back toward the bottom of the ball. In a fluid motion, Steve then puts the ball down on the lab bench and rolls it along the edge of the table, continuing to speak, "cuz of like the surface of area where it rolls" (Fig. 2e). He adds, while picking up the ball and moving his palms outward, facing each other, "so if I- if I'm spreading this surface out it's not gonna roll as much, it's gonna spin more" (Fig. 2f). While speaking, he moves his hands back together, 
holds the ball between his palms, spins it with his right thumb around its own axis, and adds, "because my- see now I'm holding it at a different point and it'll just spin” (Fig. 2g).

\section{Steve's (learner-centered) wonderfulness}

At the most basic level, we might call Steve's idea from his own perspective wonderful because he found his insights about rolling balls significant enough to not only comment on them but to act them out in a rather elaborate, multimodal display. Steve's engagement and attention to the details of his performance (gaze directed toward ball, careful placement of fingers on the ball) and his considerable efforts to obtain and monitor Sally's attention (restart [8], gaze directed toward Sally) lend additional credence to the "learner's wonderfulness" of Steve's idea.

\section{E. Disciplinary wonderfulness of Steve's idea}

Although a note in the lab manual states that friction only plays a negligible role for the energy dynamics in this scenario, Steve insists that friction is the reason for the observed difference in the time it takes the two balls to roll down their respective tracks. When Sally asks if the friction really is different for the two balls, Steve launches into an elaborate, multimodal demonstration of how the points on the ball in contact with a surface it rolls on influence rotation and translation of the ball. In fact, points toward the bottom of the ball would result in a greater effective radius for the rolling of the ball, which means more distance traveled per rotation for the ball. Contact points further up the sides of the ball would result in a smaller effective radius for rolling, which would mean less distance traveled per rotation.

Steve's idea is consistent with the explanation given in section II.A above. From a disciplinary viewpoint, Steve's idea can be considered very productive for Steve and Sally's pursuit of an explanation for the observed phenomenon. As such, we can see it as disciplinarily wonderful.

\section{F. Steve and Sally's (co-constructed) wonderfulness}

When Sally asks, "would that be called friction" (Fig. 2c), she projects silent alignment [12] with the substance of
Steve's acted-out explanation but questions "friction" as the appropriate name for it. Once Steve concludes his demonstration with the ball, Sally asks again, "yeah, but like would- is friction the correct term?" Steve invokes the authority of the lab manual by pointing to it and saying, "it says it in the bottom. note- it gives you the answer [brief pause] of why." Sally looks at her lab manual as if to confirm that the answer is indeed there and with a slight smile says "oh!" Then she turns to the board, points to it and says, "yeah, so friction." With this, Sally now displays vocal alignment with Steve's idea, the name "friction" for the idea, and its relevance for the problem at hand. Together, they have co-constructed the wonderfulness of Steve's idea.

\section{CONCLUDING REMARKS}

In my plenary talk and this paper, I argued that the notion of wonderfulness is complex and deserves to be problematized. Regardless of how we see wonderfulness, we should strive for our students "to take their own knowledge seriously, to be willing to pay attention to their confusion, to make an effort to understand each other's ways of understanding the phenomena, [and] to take the risk of offering ideas of which they are not sure" [1] (p. 84). To allow them to do that, we have to provide students with opportunities to have their wonderful ideas. As teachers and researchers, we have to be willing to accept students' ideas as what they are and be aware that ideas are not just had with words but can be (and often are) multimodal achievements.

\section{ACKNOWLEDGEMENTS}

I would like to thank Steve and Sally for their willingness to participate in the Mechanisms of Active, Collaborative Learning research project; Virginia J. Flood for many productive discussions about this work; the members of the Productive Interactions and Ideas in Physics Laboratory (PI/IP Lab) for their help with creating and analyzing many hours of audiovisual recordings; Rosemary Russ and Déana Scipio for inspiring and generative conversations while planning for our plenary talks; and the PERC 2018 organizers for inviting us to speak about wonderful ideas.
[1] E. Duckworth, "The Having of Wonderful Ideas" and Other Essays on Teaching and Learning, 2nd ed. (Teachers College Press, New York, NY, 1996).

[2] L. K. Perry, L. K. Samuelson, and J. B. Burdinie, Dev. Sci. 17, 757 (2014).

[3] A. Meek, Educ. Leadersh. 48, 30 (1991).

[4] B. W. Harrer, Identifying Productive Resources in Secondary School Students' Discourse About Energy, University of Maine, Orono, ME, 2013.

[5] J. Sidnell and T. Stivers, The Handbook of Conversation Analysis (Wiley-Blackwell, West Sussex, UK, 2012).
[6] C. Kitzinger, Fem. Psychol. 10, 163 (2000).

[7] L. Mondada, J. Socioling. 20, 336 (2016).

[8] C. Goodwin and J. Heritage, Annu. Rev. Anthropol. 19, 283 (1990).

[9] J. W. Du Bois, in Stancetaking in Discourse, edited by R. Englebretson (John Benjamins Publishing Company, Amsterdam, 2007), pp. 139-182.

[10] W. Potter et al., Am. J. Phys. 82, 153 (2014).

[11]B. W. Harrer and C. A. Paul, Phys. Teach. (in preparation).

[12] C. Baraldi, J. Bus. Commun. 50, 339 (2013). 